\title{
Claves agustinianas en la fenomenología del sí mismo de la vida fáctica
}

\author{
Augustinian keys in the phenomenology \\ of the Self of the factical life
}

\author{
AGUSTÍN PALOMAR TORRALBO \\ (Universidad de Granada)
}

\begin{abstract}
Resumen: El objetivo de este trabajo es estudiar el lugar que ocupa San Agustín en el desarrollo de la fenomenología del sí mismo que se halla incoada en la descripción de la vida fáctica que hace Heidegger en Grundprobleme der Phänomenologie (GA 58). Para ello, en primer lugar, caracteriza la fenomenología de la vida como aquella que requiere del mundo para manifestarse y, por ello, como aquello que ha de ser comprendido como vida fáctica. En segundo lugar, el artículo dilucida los rasgos de una fenomenología del sí mismo como descripción de ese mundo propio [Selbstwelt] que está imbricado en el mundo circundante [Umwelt] y en el mundo compartido [Mitwelt]. Y, por último, expone el lugar de las Confesiones de San Agustín en esa fenomenología del sí mismo a partir de lo que entraña la quaestio mihi factus sum.

Palabras Clave: vida fáctica, mundo del sí mismo, ciencia originaria, fenomenología de la vida religiosa
\end{abstract}

\begin{abstract}
The aim of this paper is to study the place of St. Augustine in the development of the phenomenology of the self that is initiated in the description of the factical life that Heidegger makes in Grundprobleme der Phänomenologie (GA 58). For that, first of all, it characterizes the phenomenology of life as the one that requires the world to manifest itself and, therefore, as what has to be understood as factical life. Secondly, the article elucidates the features of a phenomenology of the self as a description of self-world [Selbstwelt] that is interwoven with the surrounding world [Umwelt] and the communal world [Mitwelt]. And, finally, it exposes the place of Confessions of Saint Augustine in that phenomenology of the self from what the questio mihi factus sum entails.
\end{abstract}

Keywords: factical life, self-world, original science, phenomenology of religious life

Heidegger, como otros pensadores alemanes que surgieron en el siglo $\mathrm{XX}-$ Bultmann, Jonas, Jaspers, Guardini, Scheler-, valoró el pensamiento de San Agustín como una aportación decisiva para el análisis de la existencia y para la fenomenología. De todas sus obras, la que mejor servía a los propósitos del joven Heidegger era, sin duda, las Confesiones. En efecto, la obra de San Agustín está señalada en el itinerario particular de Heidegger como un lugar casi obligado en el camino hacia Sein und Zeit: por un lado, el propio texto de las Confesiones se convierte en motivo de una lectura fenomenológico-existencial, por otro, en él se indica el modo en el que puede llevarse a cabo la tarea del análisis filosófico como análisis fenomenológico, en tanto que en las Confesiones se describe 
reflexivamente el itinerario espiritual como una experiencia en la interioridad de la conciencia ${ }^{1}$. Esta vuelta a la interioridad se explica existencialmente como una reconducción o reducción de la dispersión o distensión del tiempo en el mundo a la tensión propia de quien se pone a sí mismo frente a la eternidad. «Pero el hombre - ha escrito Amengual- no es solo distensio, sino también intentio, tendencia y tensión hacia la eternidad: ahí donde se da la plenitud, la unidad, la paz, la estabilidad» (Amengual, 2011, p. 66).

Pero, a diferencia del camino de la reflexión fenomenológica trascendental de Husserl, esta fenomenología no surge primariamente como un acto de la libertad de la conciencia que se pone en actitud fenomenológica para volver a sí misma, sino como el único modo que tiene el hombre de salvarse de su hundimiento en el mundo y con él del desfondamiento de sí mismo. «El desfondamiento - ha escrito también Amengual - es la experiencia de que los propios cimientos, aquello sobre lo cual todo debería descansar, se desmoronan y se hunden, de manera que el hombre, en vez de encontrarse sólida y firmemente fundado, se encuentra en un abismo sin fondo ni fundamento» (Amengual, 2011, p. 50). Este ahondamiento en sí mismo es lo que, en definitiva, hace que San Agustín sea atractivo para cualquier análisis de la existencia en general y, en el caso específico del joven Heidegger, para la comprensión de la experiencia de la vida en su facticidad. Es en la vuelta a la interioridad donde en San Agustín las cuestiones relativas al tiempo, a la historia, a la propia existencia, al ser en general, así como las relativas a la felicidad, al orden del amor, al mal, etc. se vuelven relevantes para la investigación en la medida en que estas cuestiones se vuelven significativas en la experiencia de la propia trascendencia.

En San Agustín, en este sentido, no solo encuentra Heidegger algunos de los temas fundamentales para el análisis de la vida fáctica, sino sobre todo un modo de proceder en el que se pone a prueba una lectura fenomenológica de las Confesiones en la que se intenta dilucidar la experiencia originaria propia de la vida fáctica. En este curso, como en otros del joven Heidegger, el método fenomenológico se aclara en la lectura de los textos clásicos de filosofía, como si la fenomenología fuera el modo secreto en el que discurre la tradición filosófica y, por otro lado, desde esa orientación hermenéutica del método fenomenológico, se irradia luz para comprender el sentido de los propios textos de esta tradición. Es en estos cruces donde Heidegger encuentra la apertura de la propia fenomenología a la hermenéutica que, como se sabe, a partir de 1923 tomará la forma definitiva de una «hermenéutica de la facticidad $»^{2}$.

Sobre esta concepción de la interioridad, que tiene su origen en la fenomenología de la religión en el joven Heidegger, que se debe principalmente a San Agustín y a Lutero y que Heidegger mismo opondrá a la concepción de la interioridad cartesiana, véase Eychenié, 2016.

2 R. Rodríguez ha señalado la importancia que tiene la presencia de la fenomenología husserliana en el joven Heidegger como «el estilo y el modo de comprensión filosófica capaz de llevar a cabo con éxito la empresa de autointerpretación de la facticidad» (Rodríguez, 1997, p. 15). Esta fenomenología se orienta hacia la búsqueda del camino o del método de la experiencia fundamental que constituye la vida fáctica. Es esta búsqueda la que abriría las "cuestiones de método" en Heidegger. El método, para acceder a esta experiencia fundamental, tiene la peculiaridad de que en su puesta en práctica no puede ser tomado como algo totalmente a priori ni tampoco como algo que cabe resolver plenamente en la facticidad. La dificultad de la comprensión de la vida fáctica consiste en que la búsqueda de un método requiere ya de «"saber" algo válido de ella para poder tratarla adecuadamente» (Rodríguez, 1997, p. 14). Sobre la interpretación de este texto de R. Rodríguez, véase: De Lara, 2020. 


\section{El transcurrir de la vida fáctica en el mundo}

Pues bien, en el itinerario intelectual de Heidegger, el curso Grundprobleme der Phänomenologie (GA 58) está especialmente destacado. El mismo Heidegger lo nombra en una conocida nota a pie de página en el epígrafe 15 de Sein und Zeit resaltando la importancia de dicho curso para los análisis del mundo circundante, en particular, y para la hermenéutica de la facticidad del Dasein, en general [überhaupt] (cfr. Heidegger, 1977, p. 72).

Este texto deHeidegger puede comprenderse como un ensayo cuyo objetivo es buscar un ámbito de experiencia que pueda tornarse en ciencia originaria [Ursprungswissenschaft]. Esta ciencia, que tiene un carácter netamente preteórico, es en definitiva la filosofía en tanto que fenomenología (cfr. Xolocotzi, 2004, p. 49). Pero, también hay que poner de manifiesto que la fenomenología siempre pretendió ser desde Hegel una ciencia de la experiencia que se da de modo originario y, en tanto que originario, de un modo primero y fundamental. La cuestión ciertamente está en si esta ciencia originaria requiere que esa experiencia se dé a la conciencia en tanto que conciencia teórica, o bien esa experiencia de la conciencia es anterior a toda conciencia teórica. Para Heidegger, el ámbito originario en el que cabe forjar una fenomenología es la vida ${ }^{3} \mathrm{y}$, por tanto, la cuestión es si la vida, como vida fáctica, requiere para su manifestación originaria de la conciencia teórica.

Que la vida sea lo originario viene marcado en el texto de Heidegger con la nota de que la vida es lo "autosuficiente" [Selbstgenugsamkeit]. Que la vida sea "su autosuficiencia" es caracterizar a la vida «en un aspecto — como- el "en sí" [an sich]» (GA 58, $30 / 42)^{4}$. Con esta terminología de raigambre hegeliana, quiere Heidegger enunciar de manera precisa que el aspecto fundamental en el que se nos muestra la vida es su autosuficiencia. Una investigación sobre los problemas fundamentales de la fenomenología debe partir de este aspecto de la vida. Pero, ¿qué puede entenderse aquí concretamente por Selbstgenugsamkeit? Podría considerarse, por ejemplo, que la vida es lo que se contiene en sí de forma absoluta o lo que ya es plenamente. La vida misma, el hecho de la vida, se mostraría, de este modo, en la forma de un auto-cumplimiento en el que ella misma nos aparecería como absoluta e inmanente, de tal modo que para su descripción se bastara a sí misma. Tal concepción de la vida la encontramos, por ejemplo, en la fenomenología de Michel Henry. Sin embargo, Heidegger describe fenomenológicamente esta auto-suficiencia como una estructura intencional que no se dirige absolutamente a su propia inmanencia, sino que en su forma de cumplimiento mantiene una «direccionalidad fundamental en cada caso y siempre en un mundo [immer in eine Welt]》 (GA 58, 31/42). La vida es así lo que se pro-yecta más allá de sí misma siempre hacia un mundo. Pero, si la vida está más allá de sí misma, si el mundo es la tendencia fundamental de la vida, entonces podría considerarse que la vida no es auto-suficiente en la medida en que ella tiene al mundo como su correlato intencional. ¿Cómo puede ser auto-suficiente algo que muestra en sí

\footnotetext{
Se ha señalado que si la fenomenología es análisis descriptivo de fenómenos, no puede de antemano circunscribirse a un tipo de fenómeno particular como es la vida (cfr. Lamber, 2008, p. 86). Ahora bien, para Heidegger, la vida en modo alguno es un fenómeno particular entre otros, sino un fenómeno especialmente destacado, originario, en tanto que es el fenómeno que está en el origen de todo otro fenómeno, que es manifestación de toda otra manifestación. La vida es un fenómeno originario y precisamente, por ello, es posible que la fenomenología se caracterice como una ciencia originaria de la vida.

4 A excepción de Sein und Zeit, cito, como es habitual, las obras de Heidegger según la Gesamtausgabe incluyendo el número del volumen, la página de la edición alemana y, a continuación, la página de la traducción castellana. Ocasionalmente, se ha variado la traducción.
} 
una estructura intencional hacia el mundo? En contra de este carácter fundamental parece hablar el siguiente texto de Heidegger: «No necesita - la vida - estructuralmente salir de sí misma, librarse de sí misma, para llevar a cumplimiento sus genuinas tendencias. Ella se habla siempre solamente en su propio "idioma" [Es selbst spricht sich immer nur in seiner eigenen "Sprache” an]» (GA 58, p. 31/43).

Que la vida sea auto-suficiente no significa que la vida esté replegada sobre sí misma y que, en este repliegue, se guarde del mundo, ni que ella no pueda estar intencionalmente proyectada en el mundo que la circunda, ni que esta proyección merme en ella misma su carácter fundamental. Esto solo sucedería si seguimos pensando la "auto-suficiencia" desde el esquema metafísico teleológico y substancialista aristotélico y, a la postre, hegeliano. Que la vida sea autosuficiente quiere decir sencillamente que la vida no necesita algo fuera de sí misma para llevar a cabo el cumplimiento de sus tendencias, porque este solo puede tener lugar en un mundo. Si cabe el cumplimiento, será en el mundo. Que la vida sea auto-suficiente significa, por tanto, que ella es siempre el presupuesto fundamental que hace posible - "subyace" podría decirse si este término no llevara en sí la carga de la metafísica - que pueda mostrarse cualquier otro aspecto de ella y esto será también siempre en un mundo. La vida se basta a sí misma para llevar a cumplimiento sus tendencias porque no necesita de un télos ajeno a ella, ni necesita, por utilizar la metáfora del propio Heidegger, aprender otro idioma para hablar y manifestarse. La vida misma es lo auto-suficiente y prueba de ello es que ella misma puede im-ponerse tareas y asumir exigencias superando siempre «sus limitaciones, sus imperfecciones» y satisfaciendo «sus perspectivas» (GA 58, p. 31/43).

Lo distintivo de esta fenomenología, como decimos, es que originariamente se orienta al mundo y, por ello, será finalmente una fenomenología de la-vida-en-el-mundo. Solo sabemos de la vida en la medida en que esta tiene su lugar de manifestación en el mundo, pero, a la inversa, solo sabemos del mundo en tanto en él ya opera la vida. Ahora bien, el carácter fundamental de la vida viene dado con respecto al mundo en la forma de una trascendencia, esto es, en la forma de un ir siempre desde sí más allá de sí para aparecer ante sí en el mundo. La vida mantiene su trascendencia como apertura intencional al mundo, esto es, encuentra suficientes motivos en sí misma para manifestarse en el mundo al llevar estos a término. Heidegger dirá que «la vida tiene su motivación a partir de su propio transcurso fáctico» (GA 58, p. 31/43). Es decir, la manifestación de la vida es algo que discurre, que corre o fluye siempre más allá de sí misma en el mundo y que no puede dejar sino de ocurrir en un mundo. Si una vida no discurriera en el mundo no sabríamos muy bien qué podríamos decir de ella. Y esta tesis, que marca la trascendencia del carácter finito del pensamiento fenomenológico, apunta a que ya, en este temprano curso de Heidegger, la "vida fáctica", que luego habrá de ser simpliciter "facticidad", lleva en sí un modo de trascendencia que no es metafísica o transmundana, sino estructural e inmanentemente mundana. Es cabe el mundo cómo la vida da lugar para hablar de sí misma. Sin mundo no se abrirían itinerarios para la vida.

\section{La fenomenología como ciencia buscada de la vida originaria}

Este es el significado del carácter fundamental que se expresa con el término, todavía cercano a la tradición metafísica, de "auto-suficiencia". Una fenomenología del sí mismo ha de preguntarse ya desde estas consideraciones en qué medida la referencia al autós, como aquello que es exigido por el verbo sufficiô, puede pensarse más allá de las categorías metafísicas y si, para la comprensión de aquello a lo que alude el 
significado del verbo, basta el "sí mismo" y cómo este "sí mismo" ha de ser comprendido, a su vez, en presencia o ausencia de mundo. La cuestión ciertamente tiene que ver con la necesidad o no para el verbo de un complemento argumental, es decir, con el carácter transitivo o no de la propia acción del verbo.

Ahora bien, baste ahora señalar esto para indicar que, para Heidegger, ya desde sus trabajos de juventud, la cuestión de una fenomenología del sí mismo no puede esclarecerse sino en referencia al mundo como aquello que es por principio lo otro (héteron) del sí mismo (autós) y, sin embargo, exigido por él para su manifestación. En este sentido, sostenemos que el espejamiento de la cuestión de la vida es correlativo al esclarecimiento de la cuestión del mundo y de tal modo que, en la sintética expresión de "vida fáctica", ya está dado el contenido de esta correlación en la medida en que lo fáctico para la vida radica en el mundo. La vida fáctica se sitúa ante el mundo como pro-yecto, es decir, como aquello hacia donde puede dirigir-se, pero también como aquello desde lo que puede retornar manteniéndo-se siempre, en este ir y venir, en su facticidad. La experiencia en sí misma de la vida en su estar en el mundo es lo que determinará el juego de las posibilidades que se abren para ella en el mundo en su carácter fáctico y las que se abren para sí misma en ese volver cabe sí de su experienciarse en el mundo. Ahora bien, para el joven Heidegger, la fenomenología se ofrece como la ciencia que puede dar cuenta de esta experiencia originaria de la vida en el mundo y, por ello, la experiencia que está en el origen mismo de toda otra consideración — vale decir "interpretación" - de la vida. La fenomenología es, en este sentido, para Heidegger, como lo fue para Husserl, la ciencia de lo radical que, volviendo a los orígenes, da cuenta de las raíces de todas las cosas — rizōmata pantōn- (cfr. Hua XXV, 61). La fenomenología es la ciencia que da cuenta del desarrollo de la vida desde su raigambre en el mundo.

Pero, esta ciencia buscada entraña el problema fundamental de si la vida puede ser elevada al orden del conocimiento de una ciencia primera. Pues bien, para Heidegger, esta ciencia tiene que «rechazar sin miramientos todo intento de idearla a ella misma, o bien el modo como ella se pone en vida, a partir de construcciones conceptuales abstractas, así como de paralizarla con conceptos ordenadores formales - objetivando el resultado-》 (GA 58, p. 2/16). "Idear" [er-denken $]^{5}$ viene a significar aquí entender este origen como algo dado en una idea. La vida es aquello que, en su origen, no puede ser "ideado", cabe decir "idealizado", ni puede ser llevado a una idea a partir de conceptos. Desde la fenomenología de la vida fáctica, según ha sido caracterizada, esta ideación no es posible en tanto que a la propia vida no cabe comprenderla desde los conceptos formales, sino que, por el contrario, son estos los que han de ser comprendidos como un desarrollo particular de la vida. Si lo originario es la vida, esta no puede hacerse traslúcida ni ser espejada en sí misma desde las ideas. Es como si la claridad de las ideas refractara aquel en sí de la vida que se presenta en su facticidad. Por ello, más bien, para Heidegger, que la vida fáctica sea lo originario significa que en su propia trascendencia inmanente traspasa los propios conceptos en los que ella pretende pensarse. Por ello, estos conceptos tan solo pueden ser tomados como funciones en las que la propia vida fáctica se ex-presa. El origen de la descripción de la vida no brilla, por decirlo de este modo, a luz de la idea, sino como aquello que muestra una opacidad primera como condición misma de su mostrarse fáctica y autosuficientemente.

En nuestra propia lectura, es esto especialmente importante, porque, con ello, se señala la razón por la cual la vida fáctica se orienta proyectivamente hacia el mundo: solo en su discurrir, solo en su propio trascender más allá de misma, más allá de los

Término marcado en la edición de la GA en cursiva. 
propios conceptos donde pretende clarificarse, puede ella misma experienciándose alcanzar una comprensión de sí. Evidentemente, ya desde aquí, puede establecerse que, para Heidegger, la cuestión de la dilucidación de la experiencia a la luz de las ideas conllevaba el compromiso con una concepción metafísica de la filosofía, según la cual, por ejemplo, bastaría el propio análisis de la experiencia a la luz de estos conceptos para comprenderla. Por decirlo de otro modo, es la autosuficiencia originaria lo que fuerza a la existencia a ser experiencia en el mundo. Que la vida tenga carácter mundano, significa que la vida sabe de sí en el modo como se manifiesta en el mundo. Solo nos puede conducir a la vida la realización concreta de ella misma siguiendo en ese camino su propia realización. Esta es la tendencia fundamental a la que debe atender la investigación fenomenológica, lo cual implica que la investigación no parta de un concepto abstracto de la propia vida y que esta no quede detenida, en su propia ex-posición, en meros conceptos que determinan solo formalmente el orden de la experiencia del mundo. Estos conceptos son llamados aquí por Heidegger «conceptos ordenadores formales [formalen Ordnungsbegriffen]» (GA 58, p. 2/16).

Aquí radica, en definitiva, que el método fenomenológico sin ser diferente de la cosa misma pueda dar cuenta de ella. Heidegger insiste, en estas primeras páginas, en que el estudio de la fenomenología no puede consistir en adquirir conocimientos sobre la propia fenomenología, no se trata de acumular conocimientos sobre los textos de los fenomenólogos y conocer con detalle la literatura secundaria sobre ellos, sino en saber seguir adecuadamente el desarrollo mismo de la vida en su querencia de mundo. Por esta razón, dice Heidegger que la fenomenología debe alejarse de esa tendencia tan poco fenomenológica de leer las propias investigaciones fenomenológicas como se lee a Spengler (cfr. GA 58, pp. 15/28-29). Si la vida no estuviera en el origen, no sería posible la fenomenología en tanto que el fenómeno siempre requiere en su aparecer originariamente de algo que es vivido; dicho de otra manera, solo aquello que es vivido, que se torna vivencia, puede llegar a aparecérsenos de un determinado modo. Heidegger dirá de este primer concepto de fenómeno lo siguiente: «Lo que le importa a la vida, aquello en lo que esta queda absorbida, se presenta siempre, se da "de algún modo" [gibt sich “irgendwie”]» (GA 58, p. 49/61). Este es un primer concepto de fenómeno que Heidegger, al comienzo del curso, viene a caracterizar como aquello que, saliéndonos al encuentro, se nos aparece ${ }^{6}$.

\section{La posibilidad de una ciencia fenomenológica sobre el sí mismo}

Pero, ¿cómo se nos manifiesta la vida fáctica en su originariedad? Pues bien, la vida fáctica se nos muestra como una «multiplicidad de estratos de manifestación que se atraviesan mutuamente» (GA 58, p. 41/53), según reza el título del propio capítulo segundo. La vida se nos muestra de facto bajo una diversidad de modos de manifestación que no están aislados unos de otros, sino co-implicados, entrelazados e interpenetrados. Como dice De Lara (2018, p. 41), esto permite entender la vida en términos históricos como «un entramado de motivos y tendencias que se entrelazan formando un tejido». Este entramado es lo que manifiesta la vida en la gran riqueza de sus motivos y tendencias. Y, por tanto, en la medida en que ella propende desde sí misma, esto es, desde su autosuficiencia, a desarrollar, movida por sí misma, en la diversidad de sus motivos, sus propias tendencias, la vida fáctica también lleva en sí la intención de

Sobre el concepto de fenómeno aquí véase: De Lara, 2008, pp. 234-256.

Studia Heideggeriana, Vol. X, 2021 
llevar a cumplimiento los diversos modos y grados en los que originariamente se manifiesta. Heidegger dirá hacia el final del curso que las tendencias siguen y desarrollan los motivos determinados de la vida y que esta es la relación fundamental de motivo a tendencia ${ }^{7}$, aunque también es el caso que motivos y tendencias puedan intercambiar sus funciones, es decir, que los motivos tengan su origen en las tendencias. Que esto sea posible no viene sino a mostrar que el sí mismo, más allá de comprenderse en su facticidad objetivamente, esto es, de experienciarse en sus motivos y tendencias, como si la relación entre ambas obedeciera a un desarrollo predeterminadamente objetivo, se experiencia como el que, en su origen, en su génesis, se da toda relacionabilidad en la que se manifiesta la vida. Es decir, el sí mismo se experiencia como el que no puede objetivar-se en las relaciones en la que él mismo originariamente se manifiesta. La relacionabilidad rompe con cualquier orientación objetivadora con la que el sí mismo se pretenda conocer y pensar.

Ahora bien, la pregunta fundamental aquí es la siguiente: qué es lo que hace posible que la vida fáctica pre-tenda llevar a cumplimiento sus tendencias en el mundo, qué pone en movimiento que esas capas de manifestación acaben cruzándose en el afán cada una de ellas de desarrollar-se, qué pone, en definitiva, en marcha que la vida fáctica, como lo que es inobjetivable en sí mismo, quiera saber de sí en su efectuación en el mundo. Pues bien, sostenemos que esto solo es posible en la medida en que la vida fáctica se manifiesta originariamente en su propio cuestionamiento. Es porque esta vida fáctica se experiencia a sí misma en su carácter interrogativo, en su íntima inquietud de sí, podríamos decir, por lo que la vida misma exige desde sí llevar a cumplimiento sus tendencias. Que la vida misma sea autosuficiente significa desde lo alcanzado aquí que lleva en sí el ser origen en su inquietud de todo aquello en lo puede llegar a manifestarse. Porque la vida fáctica se experiencia a sí misma en la inquietud de sí — una inquietud que no tiene por qué ser formulada lingüísticamente_, puede desarrollarse en sus tendencias. Las tendencias como aquello a lo que pro-pende la vida caben ser comprendidas preteóricamente desde las inquietudes particulares desde las que se orienta la vida de un modo u otro en el mundo. "Pro-pende" quiere decir aquí aquello de lo que previamente pende la vida y aquello de lo que, luego, en el curso de su efectuación, va a de-pender. Pero, ahora bien, no es solo que el vivir de la vida fáctica esté constituido por cuestiones que la orientan estructuralmente en su quehacer en el mundo, sino que es la propia vida fáctica la que puede ser afectada a sí misma en su carácter cuestionable. Por ello, bien vistas las cosas, el desarrollo y manifestación de estas tendencias de la vida fáctica es motivado fundamentalmente por el modo en el que la propia vida se experiencia a sí misma en su carácter cuestionable y cabría decir, por tanto, finito. La autosuficiencia señala así la posibilidad misma de toda otra posibilidad que orienta tendencialmente cada uno de los desarrollos particulares y que apunta en ella misma, en tanto que posibilidad radical, a un cumplimiento total de sí misma. En el desarrollo del pensamiento del joven Heidegger a este cumplimiento le corresponde una intencionalidad plena ${ }^{8}$.

Pero, evidentemente, a la descripción fenomenológica de este desarrollo de la vida fáctica en su cuestionamiento más filosófico, le anteceden otros muchos y más cercanos a ella misma. Por ejemplo, podría señalarse que el conocimiento de la ciencia es una de estas tendencias en las que se desarrolla el trascurso de la vida fáctica en el mundo y

«Das ist der Bezug von Motiv zur Tendenz» (GA 58, p. 260).

Sobre lo que entraña este concepto en el que la intencionalidad no apunta a elementos particulares, sino a la vida como tal, véase: De Lara, 2018, p. 42, nota 22. 
que obedece a la pregunta e inquietud por disponer de un saber teórico/práctico seguro, fiable, válido, etc., aunque hay que recordar aquí que ciencias son también las ciencias históricas. Que haya múltiples estratos coimplicados, entrecruzados o atravesados puede comprenderse como diferentes desarrollos de las inquietudes iniciales de la vida fáctica, los cuales exigen, a su vez, diferentes tipos de cumplimientos, cumplimientos que tendrían en su estrato más básico las propias tendencias de la vida, luego, las modificaciones de estas tendencias y, por último, las diversas interpretaciones de esas modificaciones (cfr. GA 58, p. 43/55). Evidentemente, el análisis fenomenológico muestra que esas manifestaciones, aun en la diversidad de sus modos de manifestación, mantienen vínculos y nexos entre sí e incluso, más allá de lo apuntado por Heidegger, podrían aparecérsenos con cierta rivalidad, pero, en cualquier modo, mantendrían siempre su carácter relacional. Por ello, puede decir Heidegger que todo lo que nos muestra el análisis se nos presenta como un nexo de acontecimientos (GA, 58, p. 45/56).

Ahora bien, en esto que se nos muestra en todo nexo de acontecimientos hay siempre algo que aparece en esos diversos modos de aparecer, es decir, hay algo que siempre com-parece. La fenomenología como ciencia originaria ha de poner de manifiesto esto que aparece siempre en todo otro aparecer que aquí se nos muestra como los modos en los que la vida se manifiesta al llevar a su cumplimiento sus ínsitas tendencias y motivos. Para Heidegger, lo que siempre comparece, porque conforma la misma estructura del mundo de la vida, es el mundo circundante [Umwelt] que se muestra como el "suelo de experiencia" [Erfahrungsboden], por ejemplo, en el que se desarrolla el cumplimiento teórico de la vida en las ciencias, ya sean, como hemos apuntado, las ciencias históricas o del espíritu, ya sean, las naturales. Pero también este mundo pre-teórico hace posible que los objetos mismos pueden ser tomados como tendencias en la vida de la propia ciencia. Por ejemplo, unas monedas romanas, que perteneciendo a un mundo extinto aparecen en nuestro mundo circundante, pueden ser tomadas como materia de estudio para la arqueología.

Pero, también comparece en todo aparecer el mundo compartido [Mitwelt]. Este mundo se da en tanto que los demás con-viven conmigo y en la medida que se me presentan o se me hacen manifiestos. Esta presentación se nos da en sus acciones particulares, en su comportamiento, en su forma de hablar y de callar, pero también en sus vestimentas, en sus humores o gustos (cfr. GA, p. 45/57). Este mundo compartido es el espacio en el que los demás se nos manifiestan, como nos dirá Arendt, a través básicamente de sus palabras y acciones. Heidegger apunta a la experiencia con el prójimo como un hilo conductor de la investigación fenomenológica de la manifestación de la sociedad humana y como un suelo también de experiencia que se forja en la relación con los demás y que hace posible la creación de instituciones humanas, tales como las iglesias, las ciudades, las familias, etc.

Pero, como bien se sabe, ni un mundo ni otro se comprenden bien, sino desde el papel que desempeñan en uno y otro la comparecencia del mundo del sí mismo [Selbswelt], el cual puede ser también suelo de experiencia, en la imbricación de los otros dos mundos, para un estudio temático. Que se da esta compenetración o imbricación se hace patente en que el mundo del sí mismo mantiene un nexo con esos dos mundos, de tal modo que la propia estabilidad del mundo del sí mismo «surge [aufgeht] justamente en dicho nexo» (GA 58, p. 56/67). No es fácil, por tanto, determinar el núcleo fenomenológico que constituye este mundo. Sin embargo, lo que muestra el análisis es que no está formado «meramente como vivencias que fueron mías, sino que yo mismo tenía una cierta estabilidad [bestimmte Zuständlichkeit], era yo-mismo» (GA 58, p. 46/57). Es esta estabilidad, concreta, determinada, cierta, la que hace posible, en definitiva, 
que lo que sucede en derredor del sí mismo, ya sea el mundo general que me circunda, ya sea el mundo compartido de los otros, permanezca como experiencia retenida en el sí mismo. De este modo, queda el sí mismo en conexión, a su vez, con el pasado sido. Efectivamente, en la cuestión del sí mismo ya está delineada la cuestión de la retención de la experiencia en lo que puede ser rememorado.

Pero, Heidegger, en este curso, no se queda en la constatación de esto, ni prosigue por igual el desarrollo paralelo de cada uno de estos modos, como si de dominios particulares de ontologías regionales se tratara, sino que la descripción de la vida fáctica, en tanto que ciencia de los orígenes, se adentra en el mundo del sí mismo como hilo conductor de la investigación fenomenológica. El camino de la investigación profundiza en el modo como el sí mismo a sí mismo se encuentra, se experiencia y se expresa. Este camino toma propiamente la forma de una meditación [Besinnung]. La meditación es el modo en el que cabe encontrarse el sí mismo en sí mismo espejándo-se en una vuelta a sí de las relaciones que constituyen $s u$ mundo en el entramado de relaciones del mundo compartido y del mundo circundante. Pero, también cabe decir que en la meditación se repara en la vivencia del sí mismo como el mundo de relaciones que se despliega desde sí. Fenomenológicamente, eso que en la tradición metafísica llamamos "yo" y que se concibe como el lugar de una interioridad se toma como la base de experiencia de las múltiples relaciones del sí mismo, las cuales, sin embargo, se manifiestan para el sí mismo trascendentemente. Señalar esto es importante porque de una teoría metafísica sobre el yo, que pretenda dar razón de sí reduciendo el yo a una sustancia, no es posible hacer una descripción como si de un mundo en la complejidad de sus relaciones se tratara, sino que solo cabe penetrar especulativamente en su contenido.

Ahora bien, por tanto, para Heidegger fenomenológicamente este mundo del sí mismo muestra su modo de ser en tanto que mundo también de relaciones, porque, más allá de ser comprendido únicamente como un espacio para las vivencias, se manifiesta a sí mismo en esa relación con el mundo circundante y con el mundo de los otros. Y de tal modo que, en esa determinada estabilidad, entra en juego la comparecencia de estos otros dos mundos. El sí mismo puede ser, por ejemplo, puesto en entredicho por el mundo compartido o bien, incluso, por el mundo circundante, de igual modo que él mismo puede poner en cuestión a estos otros dos mundos que siempre comparecen fácticamente con él. La experiencia del sí mismo implica que de facto ya se está cabe sí en la trama de todas esas relaciones. Pero, afirmado esto, hay que decir inmediatamente después que para Heidegger hay una prioridad de la fenomenología del sí mismo sobre la fenomenología del mundo circundante y la fenomenología del mundo compartido, hasta tal punto que este mundo es señalado, en el centro de la vida fáctica, «de un modo especialmente acentuado» (GA 58, p. 57/68). Ciertamente, la vida fáctica en su quehacer se hace patente a sí misma en su discurrir por el mundo de forma especialmente destacada en el mundo del sí mismo, pues solo desde él la vida puede ser vista en el desarrollo de sus tendencias fundamentales. En este sentido, la aproximación a una ciencia originaria sobre la vida, esto es, a una fenomenología de la vida fáctica, tiene que destacar primordialmente el mundo de sí mismo como esfera originaria de la experiencia. ¿Dónde ha lugar para la inquietud de sí y para experienciar el cumplimiento de sus querencias, sino en el sí mismo? Pues bien, por ello, a pesar de su cierta estabilidad o de su estabilidad frágil, que lo aleja de ser comprendido en términos de una metafísica de la substancia, puede el mundo del sí mismo convertirse en el centro de una investigación fenomenológica que toma como centro la vida fáctica como vida propia de la existencia humana, la cual no es vida simplemente de la naturaleza ni tampoco, desde un punto de vista absoluto, vida del espíritu. Aunque esta vida refracte toda consideración sobre sí misma idealista, sí puede 
ser aclarada fenomenológicamente mediante la descripción de su lugar en la trama de relaciones en las que realiza sus orientaciones tendenciales.

Heidegger profundizará en el modo como este mundo del sí mismo puede ser elevado a una comprensión histórica científica en una consideración de él mismo desde un punto de vista de una tercera persona; pero también cómo puede ser descrito, cabe decir escrito, como la vida que ocurre y acontece a uno mismo en primera persona. La vida misma, la vida de uno mismo, puede volver-se escritura, auto-bio-grafia ${ }^{9}$. Y es aquí, como no podría ser de otro modo, donde Heidegger nombra las Confesiones de San Agustín como escritura testimonial, donde el sí mismo, que comparece en toda otra manifestación de la vida, comparece ahora ante él mismo.

\section{San Agustín y la ciencia de los orígenes}

En este contexto es donde, en el curso de 1919/1920, Heidegger cita por primera vez la obra agustiniana. La referencia aquí a San Agustín es marginal, pero ya nos indica cómo para Heidegger la obra de San Agustín es importante para mostrar el modo en el que la vida fáctica se "efectúa" y se "manifiesta" de forma marcada y destacada en el mundo del sí mismo y de tal manera este sí mismo se comprende de modo originariamente relacional. «Para San Agustín — ha escrito Chrétien - la existencia humana es en el fondo relacional: yo no soy lo que soy sino en la medida en que estoy ante, ante Dios, o ante los hombres, "coram Deo", "coram hominibus" [...]» (Chrétien, 2005, p. 50). La conversión al cristianismo es confesada como una fenomenología del sí mismo que se desarrolla, a su vez, como una fenomenología de la interioridad. La escritura de las Confesiones se muestra como un repliegue del desarrollo de la vida en su facticidad al núcleo originario de la experiencia en el que se pone en juego el drama interno de la salvación.

Pues bien, en los apuntes complementarios de Oskar Becker a este curso de Heidegger, se encuentra formulada magistralmente la tesis acerca de la posición privilegiada que San Agustín ocupa para Heidegger como guía para una fenomenología de la vida fáctica. A pesar de su extensión es importante citar y profundizar en este texto:

Esta conquista del cristianismo antiguo fue desfigurada y sepultada por la intrusión en el cristianismo de la ciencia antigua. De tiempo en tiempo se impone nuevamente en violentas erupciones (como en San Agustín, en Lutero, en Kierkegaard). Solo desde aquí puede entenderse la mística medieval. En las Confessiones, los Soliloquia o en De civitate Dei, San Agustín hizo valer el significado central del mundo del sí mismo para la vivencia cristiana originaria. Pero fue vencido por la lucha contra la dogmática. Se dice de San Agustín que fue un precursor de Descartes. Sin embargo, San Agustín vio el mundo del sí mismo de una manera mucho más profunda que Descartes, quien estaba influenciado por la ciencia natural moderna. La sentencia "crede ut intelligas" significa que el sí mismo debe realizarse en la vida plena antes de poder conocer. En las palabras "inquietum cor nostrum" está dado un aspecto totalmente nuevo de la vida (GA 58, p. 205/215).

\footnotetext{
La confesión puede considerarse como el modo a través del cual, performativamente, el sí mismo se encuentra a sí mismo en la exposición que hace de sí. Que la vida salga al encuentro en la confesión solo es posible si se tiene en cuenta que la aclaración de sí requiere que el sí mismo se interrogue acerca de sí mismo y que la propia interrogación, su propio estar en cuestión, forme parte de esa declaración. Es esta interrogación acerca del lugar del sí mismo la que no tiene que estar presente en la autobiografía. Sobre la confesión como género literario, que nace propiamente con San Agustín, son muy hermosas las páginas escritas en Zambrano, 2004. Sobre qué significa "confesar" desde un punto de vista religioso en San Agustín, véase: Guardini, 2013, pp. 21-22.
} 
Como decimos, este texto confirma el peculiar valor de San Agustín para Heidegger en tanto que es posible encontrar en sus escritos menos dogmáticos una vía de acceso a la investigación fenomenológica del mundo del sí mismo. Este núcleo puede ser aislado y descrito por la fenomenología si se pudiera sacar a la luz y renovarse para la reflexión aquella conquista que el cristianismo hizo con respecto al mundo antiguo y que luego volverá a perderse para la tradición filosófica moderna, exceptuando esa tradición agustiniana que pervivirá en el protestantismo con Lutero y Kierkegaard junto a místicos como Eckhart o Tauler. Para ello, la investigación solo avanzará si puede pensarse originariamente la vida en su facticidad tal y como se dio en el cristianismo primitivo y lejos aún de los elementos y esquemas categoriales que llevó a la vida fáctica a ser comprendida por el pensamiento como teología dogmática y lejos también del intento de idearla o idealizarla en su comprensión como metafísica. Para Heidegger, la cuestión de la religión, como cuestión de una relacionabilidad propia del hombre con Dios, es una cuestión fenomenológica de la vida fáctica ${ }^{10}$. Esto ha llevado a afirmar que Heidegger no leyó el cristianismo a la luz del pensamiento griego, sino, al contrario, quiso interpretar este a la luz de aquel (cfr. Savarino, 2017, p. 31).

Pero, a la luz del propio texto, hay que hacer hincapié en lo que ya aquí se ha dicho: el mundo del sí mismo es el mundo originario del corazón inquieto, una inquietud que pone en marcha el desarrollo mismo del cumplimiento de las tendencias de la vida que, en la lectura canónica de San Agustín, tomará la forma de la felicidad ${ }^{11}$. Para San Agustín, como sabemos, aquella experiencia que, en principio, se nos muestra inmanentemente lleva, acuciada por la cuestión de sí, a un cumplimiento trascendente, de tal modo que la interioridad inmanente se resuelve trascendentemente. La inquietud del corazón, metódicamente, lleva a poner de manifiesto el carecer relacional de la vida fáctica en términos de inmanencia y trascendencia, la cual llevará, en última instancia, a hallar en sí a Dios como lo más interior de sí mismo y, al mismo tiempo, como lo más superior. "Tu autem eras interior intimo meo et superior summo meo», dice San Agustín en Confesiones, III, 6, 11 (San Agustín, 1946, p. 406). La inquietud, que pone en movimiento la propia vida fáctica, tomará la forma de la quaestio mihi factus sum. San Agustín representa así un lugar destacado dentro de ese desplazamiento de la cuestión del sí mismo que trae consigo el cristianismo (cfr. GA 58, p. 61/72). Con el cristianismo, dice el joven Heidegger, «el mundo del sí mismo como tal entra en la vida y es vivido en cuanto tal» (GA 58, p. 61/72). Es este llevar la experiencia del mundo circundante y del mundo de los otros hacia el mundo del sí mismo y encontrar que en este mundo radica la vida la principal aportación del cristianismo antiguo. Es esta radicalidad la que dará al crede ut intelligas agustiniano un lugar tan destacado para la fenomenología como ciencia de los orígenes. Traducirá Heidegger este dictum agustiniano de la siguiente forma: «vive vivamente tu sí mismo [lebe lebendig dein Selbst]» (GA 58, p. 62/73). Y comenta: «San Agustín vio en el inquietum cor nostrum la gran e incesante inquietud de la vida. Ganó un aspecto del todo originario y no solo de forma teórica, sino que vivió en él y lo llevó a expresión» (GA 58, p. 62/73). En las Confesiones, como en ningún otro texto, se hace evidente que esta vida que está cabe sí es en su centro pura inquietud, inquietud que pondrá en movimiento su experienciarse

10 Para un estudio de la fenomenología de la religión en Heidegger, véase: Camilleri, 2008. La tesis de Camilleri es que en estos escritos de Heidegger puede encontrarse tanto una fenomenología general como una tentativa de delimitar una ontología de la religión. Esto muestra el interés del joven Heidegger por renovar la teología cristiana desde la fenomenología.

11 Sobre la cuestión de la relación entre felicitas y la beatitudo en San Agustín, véase: Brotón, 2003, pp.24-35. 
en el mundo circundante y el mundo compartido y que, vuelta a sí, pondrá en movimiento su experienciarse en el mundo propio. En ambos casos, experiencia de la trascendencia inmanente que, no obstante, es también trascendencia del sí mismo en la búsqueda del cumplimiento de la satisfacción de esa inquietud originaria.

\section{Fenomenología como ciencia arqueológica de la experiencia originaria}

El pensamiento de San Agustín ya está por todo lo indicado especialmente señalado como un camino que puede ser retomado para una fenomenología del sí mismo que nos puede devolver a esa experiencia originaria de la vida fáctica. Ahora bien, para ello, habría que poner de manifiesto, más allá de las sedimentaciones de la filosofía griega y, especialmente, neoplatónica, la vida en su facticidad ${ }^{12}$. Efectivamente, el propio método fenomenológico se presenta aquí como el camino que descubre las capas de experiencias más originarias de la vida. A pesar del título Augustinus und der Neuplatonismus (GA 60) — curso del semestre del verano de 1921, dictado por Heidegger justo después de haber ensayado una fenomenología de la vida fáctica religiosa tomando como base las epístolas paulinas-, puede decirse que lo que no tiene precisamente lugar en el desarrollo de este curso es una confrontación directa entre la experiencia fáctica originaria y la filosofía neoplatónica, ni mucho menos un análisis de cómo la filosofía neoplatónica entró a vertebrar filosóficamente la experiencia cristiana originaria, sino una especie de arqueología que busca desenterrar esa experiencia originaria de la vida fáctica ${ }^{13}$.

Por ello, en primer lugar, Heidegger señala que hay toda una tradición en la que el pensamiento de San Agustín se hace presente: desde la teología medieval hasta llegar incluso al pensamiento de Scheler del que dice que es «una recepción secundaria de este círculo de ideas, aderezado con fenomenología» (GA 60, p. 51/24). En esta tradición, el agustinismo ha sido filosóficamente un platonismo sobre el que se ha erigido en la filosofía moderna el ontologismo y en el catolicismo una teología dogmática marcada por la concepción del pecado y de la gracia. Es esta tradición, que ha difuminado la experiencia originaria del cristianismo, sobre la que ha actuado la ciencia crítica de la historia del siglo XIX intentando no tanto exhibir el pensamiento original de San Agustín cuanto de situarlo históricamente. Heidegger analiza la posición del teólogo Troeltsch, que procede del neokantismo, la posición del teólogo Adolf von Harnack, que procedente de la escuela histórico-crítica y también la posición filosófica de Dilthey. Troeltsch sigue el método histórico-cultural mediante el cual se pretende separar la exposición del pensamiento de San Agustín de la teología dogmática y situarlo en su contexto histórico-social. Harnack, por su parte, que pertenece a la llamada escuela liberal, pretende desde el método histórico-crítico - "histórico-dogmático" lo

12 En estos términos se expresa Uscatescu, 2005, p. 27.

13 Capelle-Dumont, en su estudio sobre la relación entre filosofía y teología en Heidegger, ha señalado que el curso del semestre del verano de 1921 Heidegger intentaría mostrar de qué modo en San Agustín el tema de la fruitio Dei constituye una nueva consideración del tema neoplatónico del gozo del Bien y de lo Bello en su diferencia con el concepto de uti. Dios sería el único objeto digno de gozo precisamente porque es el summum bomun. Pero con ello, San Agustín habría abandonado el proyecto de la vida cristiana ligada al problema de la facticidad y se habría adentrado en el marco metafísico del platonismo, donde el pensamiento se identificaría, finalmente, con el acto de una visión o contemplación. Así escribe: «Si para él -Heidegger- Dios es el "ser-presente-continuo" es en relación a este marco que el ser y Dios son pensados como "ser-constantemente-ante-los-ojos"» (Capelle-Dumont, 2012, p. 71). 
llama Heidegger en tanto que Harnack pretendía elaborar una historia de los dogmasvolver en su teología al Jesús histórico. Su lectura de San Agustín busca descubrir, más allá de la dogmática, en el pensador de Tagaste, una revitalización de la experiencia de la religiosidad (cfr. GA 60, p. 163/27). Por su parte, Dilthey, guiado por su concepción de la hermenéutica desde la que se pretendía fundamentar las ciencias del espíritu frente a las ciencias de la naturaleza, intentaba poner de manifiesto que la novedad del pensamiento de San Agustín es la absoluta realidad de la experiencia interior y la transformación de la vida anímica.

Pues bien, Heidegger delimita cada una de estas tres concepciones sucesivamente como histórico-cultural, histórico-dogmática e histórico-científica. Las tres tienen en común que se basan en métodos de la crítica histórica, aunque bajo diferentes perspectivas: la cultural, la teológico/dogmática y la científica/espiritual. La cuestión que se plantea desde estas tres concepciones es qué podemos entender por historia y, dado que cada una de ellas aborda el pensamiento de San Agustín desde una perspectiva histórica diferente, la cuestión que se plantea es el problema de la objetividad histórica. Pues bien, Heidegger parte de la tesis que en estas tres orientaciones en el estudio de San Agustín el acceso a su pensamiento tiene el mismo sentido. Tres direcciones, pero un único sentido. «El objeto (Agustín) — dice Heidegger - es contemplado desde puntos de vista diferentes (contemplado como si se contemplaran "páginas" diferentes de él [...]» (GA 60, p. 166/31). En esta metáfora, la historia de San Agustín es considerada como páginas diferentes, pero de un mismo libro, un libro que está escrito con la mano de quien ve la historia como algo histórico-objetivo. Que sea "objetivo" viene a significar aquí, en el uso de esta metonimia por parte de Heidegger, que el pensamiento es contemplado como se contempla un libro entre objetos, es decir como si el pensamiento fuera un aspecto más entre otros en los que se manifiesta la cultura, la religión o las propias cosmovisiones filosóficas. Que Agustín pueda ser leído así, siguiendo con la imagen esta metáfora absoluta, es posible porque se lo sitúa en un marco de ordenación [Ordnungsrahmen], el cual crea el trasfondo para que un texto pueda ser leído en un contexto determinado. Así las cosas, los diferentes marcos de ordenación, de alguna manera, ordenaron —en el doble sentido del término - el modo cómo San Agustín tenía que ser leído desde un punto de vista histórico. Esta ordenación es la que hace posible la objetividad del enfoque histórico. Estos marcos, que pueden ser más o menos extensos y que pueden cubrir diferentes ámbitos, son los que determinan objetivamente cómo ha de entenderse lo histórico, ya sea ora bajo el aspecto o la dirección de la cultura, ora bajo la religión, ora bajo las ciencias del espíritu.

A partir de aquí, Heidegger profundiza en las condiciones que hacen posible esta ordenación histórico-objetiva del pensamiento de San Agustín. Lo interesante es señalar que cada uno de estos tipos de ordenación ya presupone la formación de un marco de interpretación que se determina en virtud de un concepto de tiempo que tiene en su base la sucesión cronológica del tiempo histórico. El tiempo determina el objeto material de la investigación, determinando, a su vez, el modo de orientación de la propia investigación histórica. El tiempo así entendido, afirma ya aquí Heidegger, se toma como un contenido que puede ser representado objetivamente y que corresponde a una determinada época. Pero, de este modo, no se alcanza el suelo de experiencia a partir del cual surge cada una de estas interpretaciones. A la luz del curso de 1919/1920, cada uno de estos marcos, en su caso hay que tomarlo como una forma de interpretación que surge de las modificaciones de las tendencias originarias de la vida, pero no del suelo de experiencia de la propia vida fáctica. 
Pero, entonces, si la vida originaria es inquietud, interrogación de sí, cómo hemos dicho, ¿de qué modo puede pensarse originariamente también como histórica? ¿Basta la mera inquietud de sí para llevar a término el cumplimiento de esos motivos y tendencias? Pues bien, planteando el problema del lugar de San Agustín para una fenomenología de la vida fáctica en este contexto, aparece lo que aún no estaba presente en las lecciones del curso de 1919/1920: la vida que experiencia mundo en el fondo de su inquietud y que se mueve a sí misma en su trascender o discurrir en el mundo, ha de tomar para sí la decisión o resolución de manifestarse en su desarrollo en el mundo. Es esta decisión la que, sin duda, hace que la vida fáctica en su quehacer en el mundo sea originariamente comprendida como histórica. Así lo dice Heidegger: «Si la experiencia y el conocimiento históricos no pueden ser entregados a los patrones de medida del conocimiento heredados, entonces tiene que ser buscada positivamente una decisión [Entscheidung] que solo puede ser ella misma histórica» (GA 60, p. 166/31). En la segunda parte de la cláusula condicional, está ya en ciernes cómo ha de entenderse el método fenomenológico como ciencia que pretende recuperar la experiencia del origen de la vida fáctica en sí: la experiencia histórica requiere de una decisión que abra la comprensión del sentido de esta experiencia en su propia ejecución (cfr. GA 60, p. 166/31).

Y aquí se alumbra ya el sentido de una hermenéutica de la facticidad que alcanza su vuelta al origen cuando la investigación toma como "objeto" el carácter ejecutivo primario de la experiencia fáctica y muestra, en el cómo de su ejecución, la apertura de sentido de lo que entra en juego en esa experiencia. Y es entonces cuando las Confesiones adquieren un valor especial en tanto que en la quaestio mihi factus sum ya está contenida esa inquietud originaria que es en sí misma meditativamente una preparación de la posibilidad fáctica de asumir una decisión en la que la propia vida fáctica se pone en juego. Es en la propia inquietud de la quaestio donde radica la experiencia que lleva a una decisión y una decisión que no puede no llevarse a cabo, porque el no hacerlo ya sería una decisión tomada. La quaestio se eleva, por ello, por encima de otro modo de preguntar por sí, por encima de toda otra fenomenología del sí mismo que pudiera hacerse, porque en la experiencia de sí, bajo la inquietud del cuestionamiento, se comprende el sí mismo como aquel a cuya facticidad le pertenece originariamente la decisión. Evidentemente, en el propio itinerario de San Agustín esta decisión es la que está entrañada en la conversión, una conversión que adquiere la forma de unas confesiones en las que la reapropiación de la propia vida, que se desenvuelve históricamente, se hace particularmente patente en el momento en el que se decide no simplemente reorientar la propia vida, sino re-hacerla o re-fundarla nueva u originariamente. En este momento, donde ya se comprende que una decisión ha sido tomada, es donde la propia experiencia de la inquietud se experiencia como histórica. Por ello, podemos concluir, diciendo que las Confesiones de San Agustín abrieron desde su particular fenomenología del sí mismo, el sentido de la decisión, un sentido que, en el tiempo, puede alcanzarnos aún a nosotros, aunque, evidentemente, de otro modo, si es que la inquietud de la vida de tener experiencia de sí no ha muerto en la con-fusión de tantas interpretaciones que hoy llenan el lugar del pensamiento. Quizás, para ello, habría que volver, siguiendo con la metáfora, nuevamente a la primera página de esas confesiones donde la inquietud inicial permanece in-olvidablemente bien escrita. 


\section{Referencias}

AGUSTÍN, SAN (1946). Obras de San Agustín. Las Confesiones. Tomo II. Madrid: BAC. Edición Bilingüe.

AMENGUAL, Gabriel (2011). Deseo, memoria y experiencia. Salamanca: Sígueme.

BROTÓN TENA, Ernesto J. (2003). Felicidad y trinidad a la luz del De Trinitate de San Agustín. Salamanca: Secretariado Trinitario.

CAPELLE-DUMONT, Philippe (2012). Filosofía y teología en el pensamiento de Martin Heidegger. México: FCE.

CAMILLERI, Sylvain (2008). Phénomenologie de la religion et herméneutique théologique dans la pensé du jeune Heidegger. Commentaire analytique des Fondements philosophiques de la mystique médiévale (1916-1919). Dordrecht: Springer.

CHRÉTIEN, Jean-Louis (2005). La mirada del amor. Salamanca: Sígueme.

DE LARA, Francisco (2008). "El concepto de fenómeno en el joven Heidegger", en Eidos: Revista de Filosofía de la Universidad del Norte, pp. 234-256.

DE LARA, Francisco (2018). “Análisis intencional y génesis. La filosofía temprana de Heidegger (1919-1923)”, en RODRÍGUEZ (ed.). Guía Comares de Heidegger. Granada: Comares.

DE LARA, Francisco (2020). “¿Cómo leer fenomenológicamente? La transformación hermenéutica de la fenomenología como ejemplo de ejercicio hermenéutico", en Studia Heideggeriana, IX, pp. 207-224. Doi: https://doi.org/10.46605/sh.vol9.2020.104

EYCHENIÉ, Mathieu (2016). "L'intériorité de l'être dans le monde: le jeune Heidegger, lecteur d'Augustin et de Luther", en Filosofia. Revista da Faculdade de Letras da Universidade do Porto, 33, pp. 121-137. Doi: http://dx.doi.org/10.21747/21836892/fil33a8

GUARDINI, Romano (2013). La conversión de Aurelio Agustín. El proceso interior en sus Confesiones. Bilbao: Descleé de Brouwer.

HEIDEGGER, Martin (1977). Sein und Zeit, ed. F.-W. von Herrmann. Frankfurt a. M.: Klostermann. Trad. J. Eduardo Rivera, Ser y tiempo. Madrid: Trotta, 2003.

HEIDEGGER, Martin, GA 58. Grundprobleme der Phänomenologie, ed. Hans- Helmuth Gander. Frankfurt a. M.: Klostermann, 1992. Trad. F de Lara, Problemas fundamentales de fenomenología (1919/1920). Madrid: Alianza Editorial, 2013.

HEIDEGGER, Martin, GA 60. Phänomenologie des religiösen Lebens, Frankfurt a. M.: Klostermann, 1995.

1. Einleitung in die Phänomenologie der Religion (Winter semester 1920/1921), ed. M. Jung und T. Regehly. Trad. J. Ucatescu, Introducción a la fenomenología de la religion. Madrid: Siruela, 2005.

2. Augustinus und der Neuplatonismus (Summer semester 1921), ed. C. Strube. Trad. J. Muñoz, Estudios sobre mística medieval. Madrid: Siruela, 1997.

3. Die philosphischen Grundlagen der mittelalterlichen Mystik, ed. C. Strube. Frankfurt, V. Klostermann, 1995. Trad. J. Muñoz, Estudios sobre mística medieval. Madrid: Siruela, 1997.

HUSSERL, Edmund, Hua XXV, Aufsätze und Vorträge (1911-1921). Mit ergänzenden Texten. Hrsg. v. T. Nenon und H. R. Sepp. Den Haag: Nijhoff, 1987.

LAMBER ORTIZ, César (2008). "Heidegger y el proyecto de una ciencia originaria", en Veritas, 18, pp. 85-95.

RODRÍGUEZ, Ramón (1997). La transformación hermenéutica de la fenomenología. Una interpretación de la obra temprana de Heidegger. Madrid: Tecnos.

USCATESCU, Jorge (2005). "Acerca de la fenomenología de la religión en las lecciones de Heidegger sobre la fenomenología de la vida religiosa”, en HEIDEGGER. Introducción a 
la fenomenología de la religión. Madrid: Siruela.

SAVARINO, Luca (2017). Heidegger y el cristianismo. Buenos Aires: Prometeo Libros.

XOLOCOTZI YAÑEZ, Ángel (2004). Fenomenología de la vida fáctica. Heidegger y su camino a Ser y tiempo. México: Plaza y Valdés.

ZAMBRANO, María (2004). La confesión: género literario. Madrid: Siruela. 